Es por todo 10 anteriormente mencionado, entre muchas otras razones, por lo que La obra literaria de Regino $S$. Boti, de Octavio de la Suarée, jr., resulta uno de los más valiosos aportes para el estudio de las letras cubanas durante esta crítica etapa formativa de su identidad cultural y artística de que tengamos noticia hasta la fecha.

State University of New York, Old Westbury.

JESSE FERNÁNDEZ

Vicente Huidobro. Obras completas. Edición preparada y revisada por Hugo Montes. Santiago, Chile: Editorial Andrés Bello, 1976, 2 tomos.

Felicitamos al profesor Hugo Montes por su nueva tentativa de hacer una edición completa de las obras publicadas de Vicente Huidobro. Existen hasta ahora varias antologías -algunas muy importantes- de los escritos del poeta chileno: de Eduardo Anguita (Santiago, 1945), de Antonio Undurraga (Madrid, 1957), de Hugo Montes (Santiago, 1957) y de Enrique Lihn (La Habana, 1968). La edición de las Obras completas de Vicente Huidobro por Braulio Arenas (Santiago, 1964) fue una publicación importante, pero omitió dos libros enteros: Pasando y pasando y Finis Britanniae. No es tarea fácil localizar las ediciones originales de estos dos textos, así que acogemos agradecidos su inclusión en esta edición de Montes, donde están ahora recogidos todos los libros de Huidobro. También agradecemos al profesor Montes la inclusión de textos bilinguies de varios libros de la poesía huidobriana publicados originalmente en francés (Horizon carré, Tour Eiffel, Automme régulier y Tout à Coup) y la de varios poemas y artículos no recogidos en la edición de 1964.

Sin embargo, en un volumen de tanto lujo hubiéramos preferido leer los textos originales de varios escritos. Finis Britanniae, por ejemplo, aunque publicado en francés por Huidobro, aquí aparece en traducción castellana. Lo mismo sus $M a$ nifestes y Gilles de Raiz, donde hay juegos de palabras intraducibles. El bilingüismo del poeta fue un aspecto muy importante de su obra, y en una edición de las obras completas de Huidobro el lector - creemos- tiene derecho a ver los textos originales publicados por el poeta. Por lo demás, observamos una tendencia lamentable en la selección de los escritos políticos - prosa y poesía- de Vicente Huidobro. Las incursiones de Huidobro en la vida política fueron varias y a menudo temerarias. Sin embargo, en esta edición no hay nada sobre la fase ibañista ni comunista de Huidobro; nada de los escritores de Acción de 1925, año de la candidatura presidencial. $Y$ un grupo importante de poemas políticos — «Canto al Primero de Mayo», «URSS», «Está sangrando España», «Pasionaria», «España»- no se encuentran en esta edición. Acaso resulte ingrato el quejarnos por tales omisiones si comprobamos que en estos dos tomos están recogidos más escritos éditos de Huidobro que en cualquier compilación anterior; son éstas las obras completas más completas hasta ahora del poeta chileno, pero todavía falta la edición perfecta.

$Y$ nos falta también una biografía. No necesitamos más anécdotas sobre la vida - y la leyenda - del poeta, sino un estudio crítico de la vida de Huidobro con relación a sus escritos. Nos hacen falta datos exactos sobre las fechas de composición de casi todas las obras publicadas, y un estudio biográfico - quizá con manuscritos del poeta- sería una labor valiosa y utilísima. Además, una colección de las cartas inéditas de Vicente Huidobro sería de sumo interés. Citamos, por 
ejemplo, una carta sin fecha, nunca publicada ( $y$, creemos, nunca enviada) del poeta chileno al profesor Angel Flores. Parece ser una respuesta al artículo de Flores: "The Reviewer's Rejoinder», New York Herald Tribune Books, 21 de febrero de 1932. La carta está escrita en dos hojas, con una tercera hoja suelta en la cual hay una versión alternativa en manuscrito del primer párrafo. La damos a publicidad ahora por primera vez. Las dos primeras hojas están mecanografiadas; hay secciones tachadas que indicamos con corchetes; lo que subrayamos son adiciones en manuscrito por Huidobro.

\section{HoIA 1}

\section{Monsieur Angel FLORES}

Cher Monsieur,

Je constate que votre lettre n'est pas une réponse, mais une évasion. Vous affirmez de nouveau les mêmes choses dont je vous ai prouvé l'erreur, sans justifier votre affirmation [. Vous avez une gentille façon de vous dérober davant les faits.] que l'appuyant sur les racontars d'une personne interessée dans l'affaire.

1. Ma plaquette: ESPEJO DE AGUA, que vous n'avez évidemment jamais lue, n'a pas été publiée à Paris (nouvelle erreur dans laquelle vous tombez), mais à Buenos-Ayres, en 1916. Elle a été traduite par moi-même et par Juan Gris et forme la première partie de mon livre: HORIZON CARRE. Celui-ci publié à Paris en 1917. Elle serait plutôt post datée qu'anti-datée.

[Tout ce qu'un monsieur peut avoir dit à un autre monsieur, ou une dame à une autre dame, ne change rien aux faits. Cela rentre dans la catégorie des racontars. C'est peut-être très triste pour vous et pour ces messieurs ou ces dames, mais c'est comme cela. Je le regrette.]

2. Je n'ai jamais rien publié dans la revue "Les Dies». Vous vous trompez lamentablement. Rien sur une "marquise» [et aucune] ni sur une symphonie [sur] de Beethoven. [Mon premier livre de poèmes date de quand j'avais 15 ans. Il y a dans ce livre des poèmes bien plus mativais que tout ce que vous pouvez imaginer. Cela vous fera peut-être plaisir. Mais connaissez-vous les poèmes que faisaient à cet age-là les autres poètes que vous citez contre moi?] Les deux poèmes que vous citez ne sont pas (palabra imposible de leer). Vous devez me confondre avec un autre, a moins qu'ils ne soient de poèmes de mon premier livre écrit quand j'avais 15 ans et publiés sans mon consentement, après mon départ du Chili.

IIl est curieux de constater que vous citez contre moi justement mes deux ennemis, mes deux calomniateurs: un chroniqueur de modes féminines et de dentelles, qui n'a jamais rien compris à la poésie et à l'art, et un autre pauvre jeune homme que j'ai mis à la porte de mes revues et qui

\section{HOJA 2}

m'a demandé par lettre pardon de m'avoir calomnié. Je conserve cette lettre dans laquelle, à part la demande de son pardon, il mappelle son maître, son seul guide spirituel.

De nouveau avant de signer je vous défie que ma plaquette a été anti-datée et que le nom de "creationiste» fut appliqué à un autre poète avant moi.

Pourquoi donnez-vous plus de crédit à mes ennemis qu'à moi-même? Je vou- 
drais savoir quelle mystêrieuse sympathie vous incline plutôt vers eux que vers moi, quel penchant ou quel complexe freudien vous pousse vers le mensonge que vers la vérité.]

A vous donc, cher Monsieur, de fournir les preuves du contraire

Bien à vous

P. S. Merci du second article que [vous] venez de me consacrer, cette fois au sujet de mon Cid.

\section{HOJA 3}

Je constate que votre lettre n'est pas une réponse, mais une évasion. Vous affirmez de nouveau les mêmes choses [dont que] dont je vous ai prouvé l'erreur, sans justifier votre affirmation qu'en vous appuyant sur les dire de [Reverdy luimême] personnes interessées. Donc, je tiens à vous préciser encore davantage.

Fin de texto

Aquí, en este texto olvidado, admite Huidobro por primera vez que necesitó la ayuda de Juan Gris en la preparación de sus primeros poemas publicados en francés (en Nord-Sud, y después en Horizon Carré). El texto revela otros puntos interesantes sobre Huidobro (su actitud hacia Reverdy, por ejemplo) que el crítico sabrá reconocer. Una colección completa de todos los escritos de Huidobro - publicados o inéditos - sería una verdadera mina de oro para los investigadores de la poesía moderna.

Oxford, agosto 1978.

NICH OLAS HEY

JaIme AlazRaki. Versiones, inversiones, reversiones: El espejo como modelo estructural del relato en los cuentos de Borges. Madrid: Gredos, 1977.

Con esta nueva aportación el autor complementa su útil volumen anterior, $E l$ arte narrativo de Jorge Luis Borges, en busca de un principio organizador del relato aprovechando enseñanzas de los formalistas rusos y de estructuralistas franceses como Lévi-Strauss, Genette y Barthes. Después de exponer con claridad algunos de estos preceptos que le servirán de base, analiza brevemente unos treinta cuentos. Como modelo de composición, el espejo tiene sus cambiantes; la literatura no es sólo imagen del mundo, de la cultura y de los sueños del hombre, sino una constante reformulación de sí misma: el texto refleja otros textos, una historia contiene otras, una metáfora repite otra metáfora, un hecho estético recrea el sueño, el lector recrea al escritor, el yo busca al otro -que no es otro que sí mismo-. Ocupándose mayormente del plano connotativo sin olvidar el denotativo, Alazraki confirma su proposición recobrando con diligencia numerosas menciones del propio Borges del espejo como imagen. Desde luego, la demarcación no es tan tajante como se quisiera, uno deviene el otro (dicho sea de paso, hay cierto abuso del verbo "devenir», que deberá corregirse en ediciones futuras). Borges, atento siempre al lector y cuidadoso de la notación, se interesa más por la connotación. Por tanto, Alazraki se pregunta, ¿será también el espejo vehículo de una semán. tica? La respuesta ha de buscarla en la poesía, y no es simple. En última instan- 